\title{
Development of regional models of Pinus radiata height from GIS spatial data supported with supplementary satellite imagery
}

\author{
Pete Watt ${ }^{1}$, Andrew Meredith ${ }^{1}$, Chen Yang ${ }^{1}$ and Michael S Watt ${ }^{2 *}$
}

\begin{abstract}
Background: A number of data sources currently exist that can provide information on forest plantations at a range of scales over an entire rotation cycle. In particular, LiDAR is quickly becoming the technology of choice for harvest planning and providing local-scale estimates of forest structure. Its application is still limited as repeat annual acquisition at this scale is generally cost prohibitive. Development of temporally updateable models that can accurately project important metrics such as tree height between LiDAR acquisitions would be of considerable use to resource managers. The objective of this research was to develop models of Pinus radiata height using GIS spatial data supplemented with RapidEye satellite imagery.

Methods: Multiple regression models were constructed to describe maximum canopy height $\left(H_{m}\right)$ derived from LiDAR at two relatively distant study sites located in Kaingaroa and Tairua forests. A randomised selection of $300 \mathrm{~m}^{2}$ circular plots was made at both sites and average values of $H_{m}$ within these plots were used for the modelling. Sources of information used for predicting $H_{m}$ included stand age and spatial information describing environmental variables and stand productivity. This information was supplemented with spectra and vegetation ratios derived from high resolution RapidEye satellite imagery.

Results: The most robust models of $H_{m}$ that were developed for both sites included a combination of the crop age obtained from the stand GIS, Site Index (obtained from a GIS surface) and the red-edge vegetation ratio (REVI) The final models of $H_{\mathrm{m}}$ had respective $R^{2}$ of 0.99 and 0.94 for the Kaingaroa and Tairua sites. At both sites, stand age was the strongest predictor of $H_{m}$. However, the inclusion of REVI from high resolution imagery did add an updatable temporal dimension to the model. Changes in REVI are sensitive to the impacts of abiotic and biotic factors that are not captured by stand age and Site Index.
\end{abstract}

Conclusion: Applied operationally, this model can be used in a GIS environment to estimate tree height and identify areas of anomalous growth or disturbance caused by wind, snow, fire or disease.

Keywords: ALS; Airborne laser systems; Forestry; High resolution images

\section{Background}

Managers of forest resources require detailed information about their crops for planning, management and inventory purposes. Traditionally, forest inventories have been carried out through collection of ground-based measurements describing relevant crop features such as stand density, height and volume. However, as these measurements are usually taken over a limited number of plots, and

\footnotetext{
* Correspondence: michael.watt@scionresearch.com

${ }^{2}$ Scion, P.O. Box 29237, Fendalton, Christchurch, New Zealand

Full list of author information is available at the end of the article
}

then extrapolated to entire stands, they do not account for spatial variation across stands. Use of remotely sensed data within forest inventories overcomes this limitation.

Airborne light detection and ranging (LiDAR) has proved to be very useful at characterising the forest canopy in three dimensions. Since the first application of LiDAR in forestry over a decade ago (Nilsson 1996), the technology has been widely used to spatially quantify variation in tree height and crown dimensions at resolutions ranging from the stand level (Hall et al. 2005; Naesset and Bjerknes 2001), plot level (Holmgren et al. 2003; Hyyppä et al. 2001; Lim and 
Treitz 2004; Popescu et al. 2004) to individual tree level (Chen et al. 2006; Coops et al. 2004; Holmgren and Persson 2004; Persson et al. 2002; Popescu and Zhao 2008; Roberts et al. 2005; Yu et al. 2004).

The accuracy of LiDAR-derived estimates is reported to be similar to or better than manual field measurement methods for estimating tree height and volume (Naesset 2002; Watt 2005). Data obtained using LiDAR are now used operationally in Finland, Norway, Sweden, Spain, Chile, and Australia to provide forest estimates at the compartment level (Eid et al. 2004). Due to the cost of flying, application of LiDAR, is usually limited to local scales. While regional scale data is sometimes utilised (Zhao and Popescu 2009), repeat annual acquisition at this scale is generally cost prohibitive (Hudak et al. 2002).

Although not as accurate as LiDAR the use of satellite remote sensing does provide a far more cost effective means of predicting crop height. Numerous studies have shown that multispectral satellite data can be utilised in models to map important forest attributes over the land surface (McRoberts and Tomppo 2007; Donoghue and Watt 2006; Shamsoddini et al. 2013; Ozdemir 2008; Kayitakire et al. 2006). However, there are limitations to using remotely sensed data to predict stand dimensions across the entire rotation. Many studies have shown that relationships with biomass and leaf area index tend to saturate after canopy closure when spectra or indices are utilised as sole predictors of stand dimensions (Donoghue and Watt 2006; le Maire et al. 2011). Indices are often favoured as they are likely to be less sensitive to changes in solar illumination and atmospheric conditions than individual bands. Although it is generally accepted that use of remotely sensed data relies on local calibration, little research has evaluated the robustness of relationships when they are applied across different locations.

Spatial information held in geographic information systems (GIS) is also useful for developing models of tree growth. This approach has considerable merit as forest managers generally have access to GIS and a number of potentially useful predictive variables. Rapid increases in the capability of GIS over recent years have seen the development of spatial surfaces covering a diverse range of climatic (Leathwick and Stephens 1998; Leathwick et al. 2003; Tait et al. 2006) and edaphic variables (Watt and Palmer 2012) that in combination with stand information such as age, can be used to model tree productivity. These environmental surfaces have been successfully used to improve empirical growth models (Dzierzon and Mason 2006) and to develop spatial surfaces describing indices of plantation productivity, at a given age, such as Site Index (Palmer, Hock et al. 2009; Watt et al. 2009; Palmer et al. 2012).

Prediction of forest dimensions using data obtained from GIS surfaces and satellite imagery has been less widely researched. Previous research has shown gains in predictive power when models of important stand dimensions are created using spectral data and stand age (le Maire et al. 2011; Gebreslasie et al. 2010; Zheng et al. 2004), relevant indices of productivity (Gebreslasie et al. 2010) and bioclimatic data (Baccini et al. 2008). The present authors are unaware of any research that has investigated the relative contributions of satellite imagery and all three described components of GIS spatial data in prediction of forest dimensions. The objective of this research was to develop models of Pinus radiata height using GIS spatial data supplemented with high resolution satellite imagery.

\section{Methods}

Study sites

Airborne LiDAR and high resolution $(5 \mathrm{~m})$ satellite imagery (RapidEye) were acquired over two forests with contrasting topography (Table 1) located in the North Island of New Zealand (Figure 1). The first dataset was obtained from a 4,000 ha strip located on predominantly flat terrain (Table 1) within Kaingaroa forest in the central North Island. The second dataset included all of Tairua forest, a larger (8,900 ha) undulating area (Table 1) located $160 \mathrm{~km}$ to the northwest of Kaingaroa forest (Figure 1). Key LiDAR and RapidEye attributes of both datasets are summarised in Table 2.

\section{LiDAR dataset}

The LiDAR surveys were flown using a fixed-wing aircraft during April/June (Kaingaroa site) and July (Tairua site) 2012 using a small footprint $(\sim 0.20 \mathrm{~m})$ Optech ALTM 3100EA system. The LiDAR and flight parameters used to achieve pulse densities of 4 and 2.38 returns $\mathrm{m}^{-2}$, respectively, for the Kaingaroa and Tairua sites are summarised in Table 2. The LiDAR data were processed using customised routines that were developed using Fusion software (McGaughey and Carson 2003). Outputs included a Digital

\section{Table 1 Variation in LiDAR maximum height, stand age, Site Index, mean REVI, and other key climatic and topographic metrics across the two study sites}

\begin{tabular}{lrr}
\hline Variable & & Site \\
\cline { 2 - 3 } & $19.9(0.63-48.9)$ & $25.0(0.57-45.7)$ \\
\hline LiDAR maximum height $(\mathrm{m})$ & $13.1(1-32)$ & $16.5(1-32)$ \\
Age (years) & $29.5(25.6-32.5)$ & $30.9(27.1-34.1)$ \\
Site Index (m) & $0.54(0.10-0.70)$ & $0.39(0.02-0.54)$ \\
REVI & $537(440-697)$ & $127(8-335)$ \\
Elevation $(\mathrm{m})$ & $2.35(0.36-19.1)$ & $13.5(0.42-38.4)$ \\
Slope (deg.) & $10.5(9.7-11.1)$ & $13.8(12.7-14.4)$ \\
Mean annual rainfall $(\mathrm{mm})$ & $1,545(1,452-1,704)$ & $2,019(1,836-2,364)$ \\
Mean annual temp. $\left({ }^{\circ} \mathrm{C}\right)$ &
\end{tabular}

The mean is given followed by the range, in brackets. 


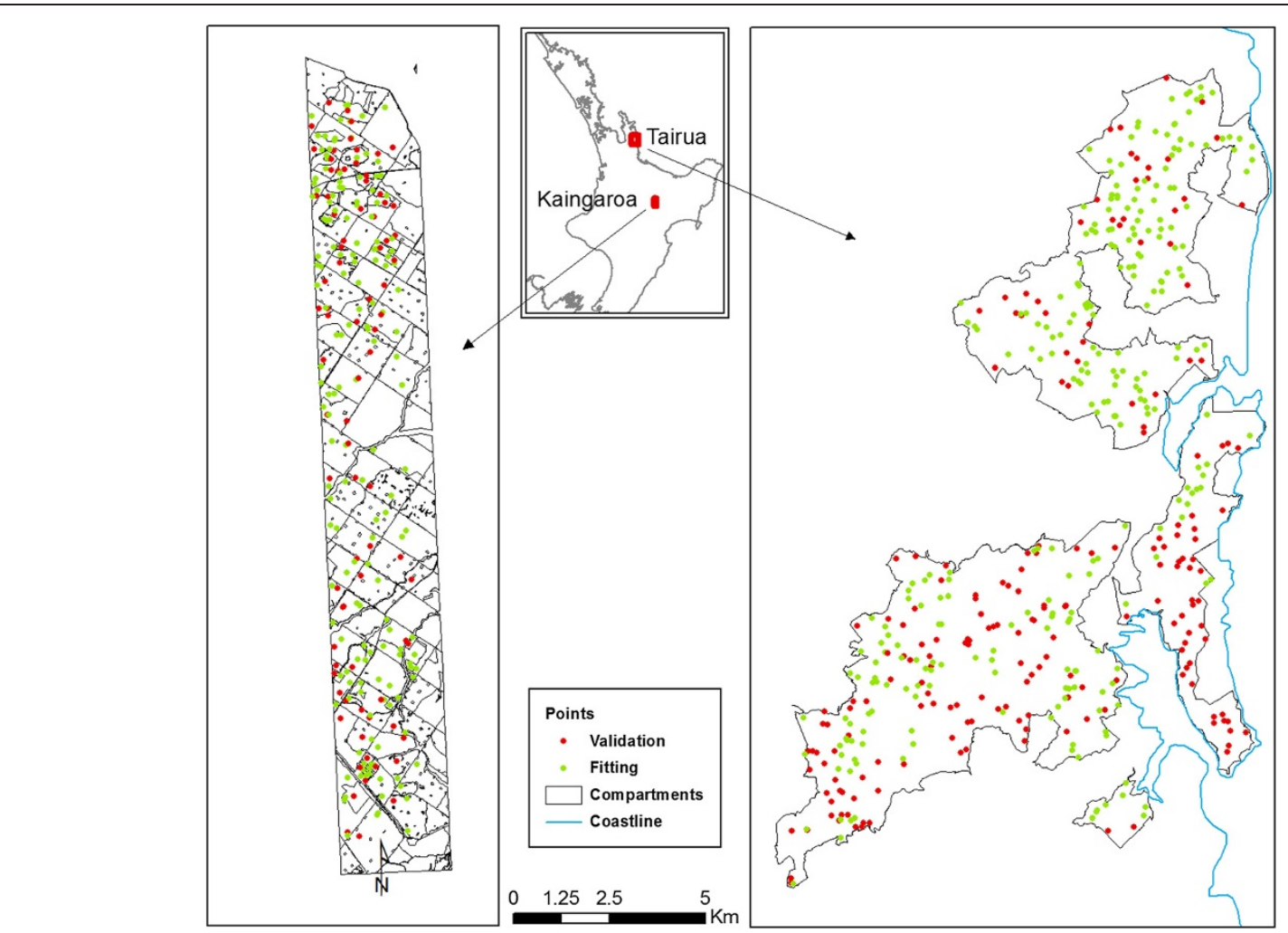

Figure 1 Map showing the location of the plots within both Kaingaroa and Tairua study areas.

Table 2 LiDAR and RapidEye specifications for the two study areas

\begin{tabular}{lrr}
\hline Variable & Site \\
\cline { 2 - 3 } & Kaingaroa & Tairua \\
\hline LiDAR specifications & 4000 & 8900 \\
\hline Survey Area (ha) & April/ June 2012 & July 2012 \\
Survey date & 4 & 2.38 \\
Pulse density (pulses $\mathrm{m}^{-2}$ ) & 1064 & 1064 \\
Wavelength (nm) & \pm 6 & \pm 6 \\
Scan angle (deg.) & 70 & 71 \\
Pulse frequency (kHz) & 70 & 53 \\
Scan frequency (Hz) & $\sim 0.20$ & $\sim 0.20$ \\
Footprint diameter (m) & 105 & 105 \\
Ground speed (knots) & 950 & 1650 \\
Flying height (m agl) & & \\
RapidEye specifications & 27 March 2012 & 2 May 2012 \\
\hline Image date & 5 & 5 \\
Resolution (m) & 5 & 5 \\
Spectral bands (No.) & 46 & 35 \\
Sun Angle (deg.) & &
\end{tabular}

Terrain Model (DTM) and a normalised digital canopy height model. Both were processed to match the spatial resolution of the $5 \mathrm{~m}$ RapidEye images. Vertical accuracy surveys based on field data collected in open land-cover areas reported root mean square error (RMSE) values of $0.05 \mathrm{~m}$ and $0.11 \mathrm{~m}$, respectively, for the Tairua and Kaingaroa sites.

\section{RapidEye imagery}

Three Rapideye scenes were acquired over the two study sites. Images were selected that were close to the date of the LiDAR survey (see Table 2) with a low level of cloud cover. The quality of each image geo-correction was evaluated against both the LiDAR and stand GIS data and rectifications were made so that the resulting image registration was accurate to a single-pixel resolution $(5 \mathrm{~m})$. The impact of topographic shadowing was reduced by applying a topographic correction. This correction adjusts the reflectance of each pixel to a horizontal surface using slope and aspect information extracted from a DTM and the sun angle recorded for each scene. The C-correction method defined in Riano et al. (2003) was applied using a $25 \mathrm{~m}$ DTM that was resampled to match the $5 \mathrm{~m}$ RapidEye image using bilinear interpolation. 


\section{Plot selection}

A randomised selection of $300 \mathrm{~m}^{2}$ circular LiDAR plots were made across both forests from the LiDAR normalised canopy height model. The forest GIS data were used to select those plots that fell inside $P$. radiata stands across the two study sites. This selection was further refined by discarding plots that fell in unstocked gaps or inside stands that were either irregular in shape or less than five hectares in size. After these exclusions, a total of 247 and 469 plots from the Kaingaroa and Tairua study sites, respectively, were available for analyses. The distribution of these plots and the area covered with the LiDAR is shown in Figure 1.

\section{Data extraction for analyses}

Maximum canopy height $\left(H_{\mathrm{m}}\right)$ for plots was extracted and used as the dependant variable in all analyses. Stand age for each plot was obtained from the stand GIS data.

RapidEye imagery that was spatially coincident with the plots was extracted. From this imagery, reflectance bands were extracted and used in analyses. These reflectance bands were used to determine two different vegetation indices, shown to correlate well with changing densities of canopy leaf area and canopy structure. These included the Normalised Difference Vegetation Index (NDVI), determined as,

$$
N D V I=\left(\frac{\rho_{\mathrm{NIR}}-\rho_{\mathrm{Red}}}{\rho_{\mathrm{NIR}}+\rho_{\mathrm{Red}}}\right)
$$

where the difference in reflectance from the near infrared $\left(\rho_{\text {NIR }}\right)$ and red $\left(\rho_{\text {Red }}\right)$ bands is divided by the sum of the two reflectances. The Normalised Difference Red-Edge Index $(R E V I)$ takes advantage of the narrow spectral range located between the red-edge reflectance $\left(\rho_{\text {Rededge }}\right)$ and near infrared bands and is determined from,

$$
R E V I=\left(\frac{\rho_{\mathrm{NIR}}-\rho_{\text {Rededge }}}{\rho_{\mathrm{NIR}}+\rho_{\text {Rededge }}}\right)
$$

The REVI is more sensitive to changes in chlorophyll concentrations than NDVI. Values for REVI range from -1 to +1 with the index differentiating bare soil at values close to 0 from actively photosynthetic vegetation where values approach 1 .

For this study, the band ratios are of particular interest as they provide an effective way to correct for variations in the reflectance that may be caused by differences in atmospheric or sun illumination conditions. This partially negates the need to conduct pre-processing steps such as atmospheric correction.

Environmental data for plot locations were extracted from biophysical GIS surfaces that included primary and secondary terrain attributes (Palmer 2008), biophysical surfaces (Leathwick et al. 2003) and monthly and annual climate data (Mitchell 1991; Leathwick et al. 2002). Key environmental variables used in analyses included mean annual and monthly air temperature, relative humidity, solar radiation, vapour pressure deficit and rainfall. A spatial soil water balance model developed for $P$. radiata (Palmer, Watt et al. 2009) was used to determine mean annual and seasonal root-zone water storage $(W)$ for all plot locations. Fractional available root-zone water storage, $W_{\mathrm{f}}$, was determined from these data and the maximum available root-zone water storage, $W_{\max }$, as $W / W_{\max }$.

Site Index, which is a standardised measure of height productivity for a site, is defined for $P$. radiata as the mean top height (the average height of the 100 largest diameter trees per hectare) at age 20 years. Values of Site Index for the plots were extracted from a New Zealand surface described in detail in (Palmer, Hock et al. 2009). This surface was developed from Site Index data obtained from an extensive set of permanent sample plots $(n=1,764)$ established across the environmental range over which $P$. radiata forests occur within New Zealand.

\section{Analyses}

All analyses were undertaken using SAS software (SASInstitute-Inc. 2000). Two separate models of $H_{\mathrm{m}}$ were developed for each of the study sites. Approximately two-thirds of the data was used for model fitting ( $n=165$ plots for Kaingaroa; $n=312$ plots for Tairua) while the remaining one-third was set aside for model validation ( $n=82$ plots for Kaingaroa; $n=157$ plots for Tairua).

For both models, a multiple regression approach was taken to predict $H_{\mathrm{m}}$ from age, Site Index, environmental data and RapidEye spectra and indices. Variables were introduced sequentially into each model starting with the variable that exhibited the strongest correlation until further additions were not significant or did not substantially improve the model performance. Variable selection was undertaken manually, one variable at a time. Plots of residuals were examined prior to variable addition to ensure that the variable was included in the model using the least biased functional form.

Accuracy and bias, were assessed on both the fitting and validation datasets for both models. To assess bias predicted values for $H_{\mathrm{m}}$ were plotted against actual values and residual values were plotted against all variables in the model. Model accuracy was determined through examining the coefficient of determination $\left(R^{2}\right)$ and RMSE.

A further check on the model was made by differencing the LiDAR height surface (which is used as the benchmark) from the surface predicted using the final model of $H_{\mathrm{m}}$ for both study sites. The difference surface was generated at the native resolution of the RapidEye image. Two surfaces were created that included the absolute difference 
between the LiDAR and the predictive surface and this absolute difference expressed as a percentage of the LiDAR height. Spatial predictions of $H_{\mathrm{m}}$ excluded recently harvested stands and stands with species other than $P$. radiata.

\section{Results}

\section{Data range}

Maximum height obtained from the LiDAR ranged widely within both datasets from ca. $1 \mathrm{~m}$ in both study sites to $49 \mathrm{~m}$ at the Kaingaroa site and $46 \mathrm{~m}$ at the Tairua site (Table 1). Age ranged from 1 to 32 years at both sites. Although mean Site Index was slightly higher at the Tairua than the Kaingaroa site, the range in Site Index was relatively similar between sites at $c a .7 \mathrm{~m}$ (Table 1). Mean values for REVI were higher at the Kaingaroa site than the Tairua site. The mean annual rainfall at both sites was similar although Tairua was substantially warmer than the Kaingaroa site. The terrain at the Tairua site ranged from flat to very steep and was considerably steeper on average than the relatively flat terrain at the Kaingaroa site (mean slope of 13.5 vs. $2.35^{\circ}$ ). The Kaingaroa site was located at a considerably higher elevation than the Tairua site (Table 1).

\section{Predictive models \\ Kaingaroa}

At the Kaingaroa site, maximum LiDAR height was most strongly correlated with tree age (Figure 2a). Age accounted for $98 \%$ of the variance in $H_{\mathrm{m}}$ and the RMSE of a model with only this variable was $1.73 \mathrm{~m}$ (Table 3). Combining age with Site Index reduced the RMSE to $1.46 \mathrm{~m}$ while a model with age and mean REVI had an RMSE of $1.52 \mathrm{~m}$ (Table 3). The final model constructed using Age, Site Index and mean REVI from the fitting dataset had an $R^{2}$ value of 0.991 and RMSE of $1.29 \mathrm{~m}$ (Table 3). For the final model, values of $H_{\mathrm{m}}$ showed little bias when plotted against predictions (Figure 3a) or when residual values were plotted against any of the variables in the dataset (data not shown). Models were similarly ranked using the validation dataset, with the final model having an $R^{2}$ value of 0.990 and RMSE of $1.37 \mathrm{~m}$ (Table 3). Using the validation dataset there was little apparent bias when predictions were plotted against actual values (Figure 3c).

Partial response functions for the final model show that $H_{\mathrm{m}}$ was most sensitive to changes in age, with values of $H_{\mathrm{m}}$ increasing $45.3 \mathrm{~m}$ across the age range in the dataset (Figure 4a). There was considerably less sensitivity between $H_{\mathrm{m}}$ and Site Index with values of $H_{\mathrm{m}}$ increasing $2.8 \mathrm{~m}$ across the Site Index range (Figure $4 \mathrm{~b}$ ). The relationship between $H_{\mathrm{m}}$ and mean REVI was characterised by an upward opening polynomial with values of $H_{\mathrm{m}}$ ranging $5.1 \mathrm{~m}$ across the mean REVI range and reaching minimum values at a mean REVI value of 0.44 (Figure 4c).

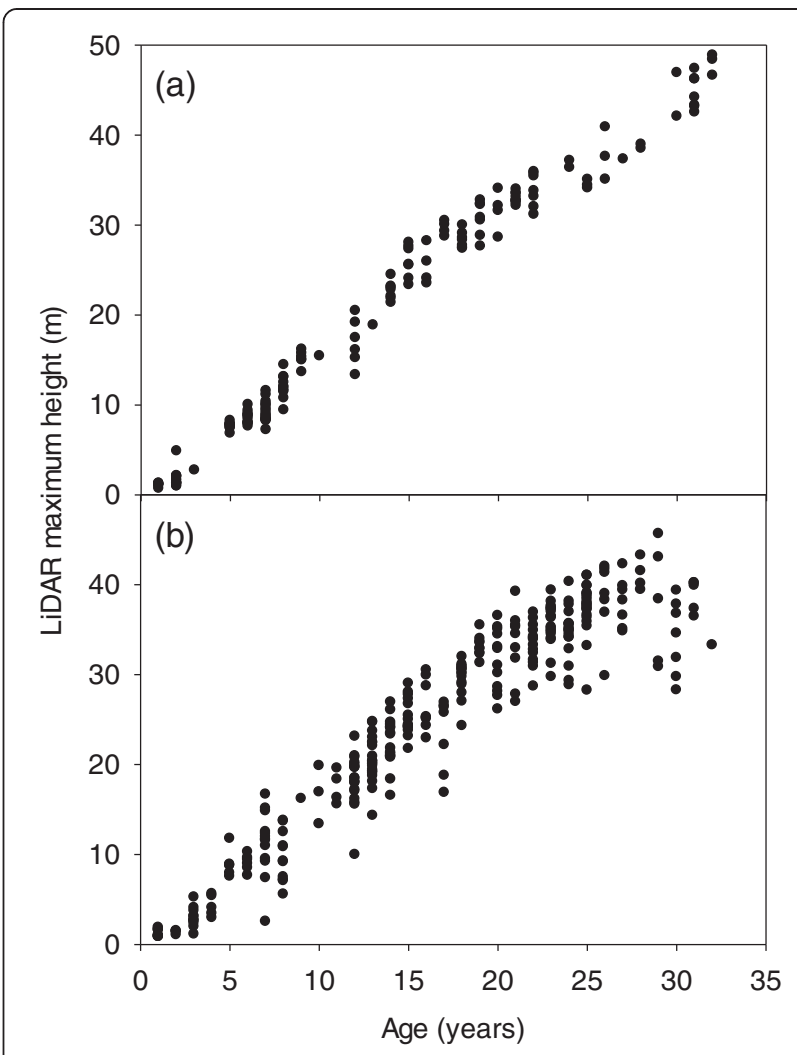

Figure 2 Relationship between LiDAR maximum height and age. The relationship is shown for (a) Kaingaroa and (b) Tairua forests.

\section{Tairua}

Tree age was the strongest determinant of $H_{\mathrm{m}}$ at the Tairua site accounting for $93 \%$ of the variance in the dataset (Figure 2b) with RMSE of $3.13 \mathrm{~m}$ (Table 4). Inclusion of either Site Index or mean REVI, with tree age, reduced the RMSE to $3.02 \mathrm{~m}$ and $3.07 \mathrm{~m}$, respectively (Table 4). The final model with age, Site Index and mean REVI had an RMSE of $2.96 \mathrm{~m}$ and $R^{2}$ of 0.936 (Table 4). There was little apparent bias in the final model when predicted values were plotted against actual values (Figure $3 \mathrm{~b}$ ) or residual values were plotted against the variables in the final model (data not shown).

When fitted to the validation dataset, the most precise model included only the variables of age and Site Index. The full model, developed using the fitting dataset, had a similar precision to the earlier model that included only age as a variable. Using the validation dataset, there was little apparent bias when predictions were plotted against actual values (Figure $3 \mathrm{~d}$ ).

Maximum LiDAR height was most sensitive to age with $H_{\mathrm{m}}$ ranging $41.5 \mathrm{~m}$ across the dataset (Figure $4 \mathrm{a}$ ). The impact of Site Index on $H_{\mathrm{m}}$ was not as marked with values of $H_{\mathrm{m}}$ ranging $4.4 \mathrm{~m}$ across the Site Index range (Figure 4b). Similarly, there was little sensitivity to mean REVI, with a range of $7.0 \mathrm{~m}$ occurring across the range 
Table 3 Summary of statistics for the four regression models of maximum LiDAR height developed using data from Kaingaroa forest

\begin{tabular}{|c|c|c|c|c|c|}
\hline \multirow[t]{2}{*}{ Model no } & \multirow[t]{2}{*}{ Variables included } & \multicolumn{2}{|c|}{ Fitting dataset } & \multicolumn{2}{|c|}{ Validation dataset } \\
\hline & & $R^{2}$ & RMSE (m) & $R^{2}$ & RMSE (m) \\
\hline 1 & Age & 0.984 & 1.73 & 0.982 & 1.83 \\
\hline 2 & Age, Site Index & 0.989 & 1.46 & 0.986 & 1.61 \\
\hline 3 & Age, Mean REVI & 0.988 & 1.52 & 0.988 & 1.52 \\
\hline 4 & Age, Site Index, Mean REVI & 0.991 & 1.29 & 0.990 & 1.37 \\
\hline
\end{tabular}

Shown are the coefficient of determination $\left(R^{2}\right)$ and root mean square error (RMSE) for the fitting and validation datasets. All variables in the four models were significant at $P<0.001$.

in mean REVI (Figure 4c). The relationship between $H_{\mathrm{m}}$ and mean REVI was characterised by an upward opening polynomial with minimum $H_{\mathrm{m}}$ reached at mean REVI of 0.38 .

\section{Predictive surfaces}

For both forests, surfaces of $H_{\mathrm{m}}$ predicted using the final models (Figures $5 \mathrm{~b}$ and $6 \mathrm{~b}$ ) corresponded reasonably well to $H_{\mathrm{m}}$ derived from the LiDAR (Figures $5 \mathrm{a}$ and $6 \mathrm{a}$ ). Surfaces showed absolute differences between the two surfaces to be less than $6 \mathrm{~m}$ or $30 \%$ in most areas within both sites (Figure $5 c, d$ and $6 c, d$ ). At the Tairua site the large percentage differences were often associated with stands with low $H_{\mathrm{m}}$ derived from the LiDAR (areas shaded red in the bottom left of Figure 6d). In these areas absolute differences between modelled and LiDAR derived were relatively low (Figure 6c).

\section{Discussion}

This study clearly showed that precise models of tree height can be developed using stand age and a GIS surface describing Site Index. Supplemental information describing REVI, obtained from fine resolution satellite imagery, significantly improved the models but this information was of secondary importance to use of GIS layers. Although of secondary importance, use of REVI does provide a temporally updateable component to the height models that could potentially account for the impact of abiotic and biotic factors on tree height.

At both study sites, age was the strongest determinant of $H_{\mathrm{m}}$. Comparison of partial response functions show that age exceeded the contribution of other variables by at least nine-fold at Kaingaroa and six-fold at Tairua. The strength of the age-height relationship was largely attributable to the relatively narrow range in Site Index at both sites, which varied by $c a .7 \mathrm{~m}$. Site Index often varies more widely at a

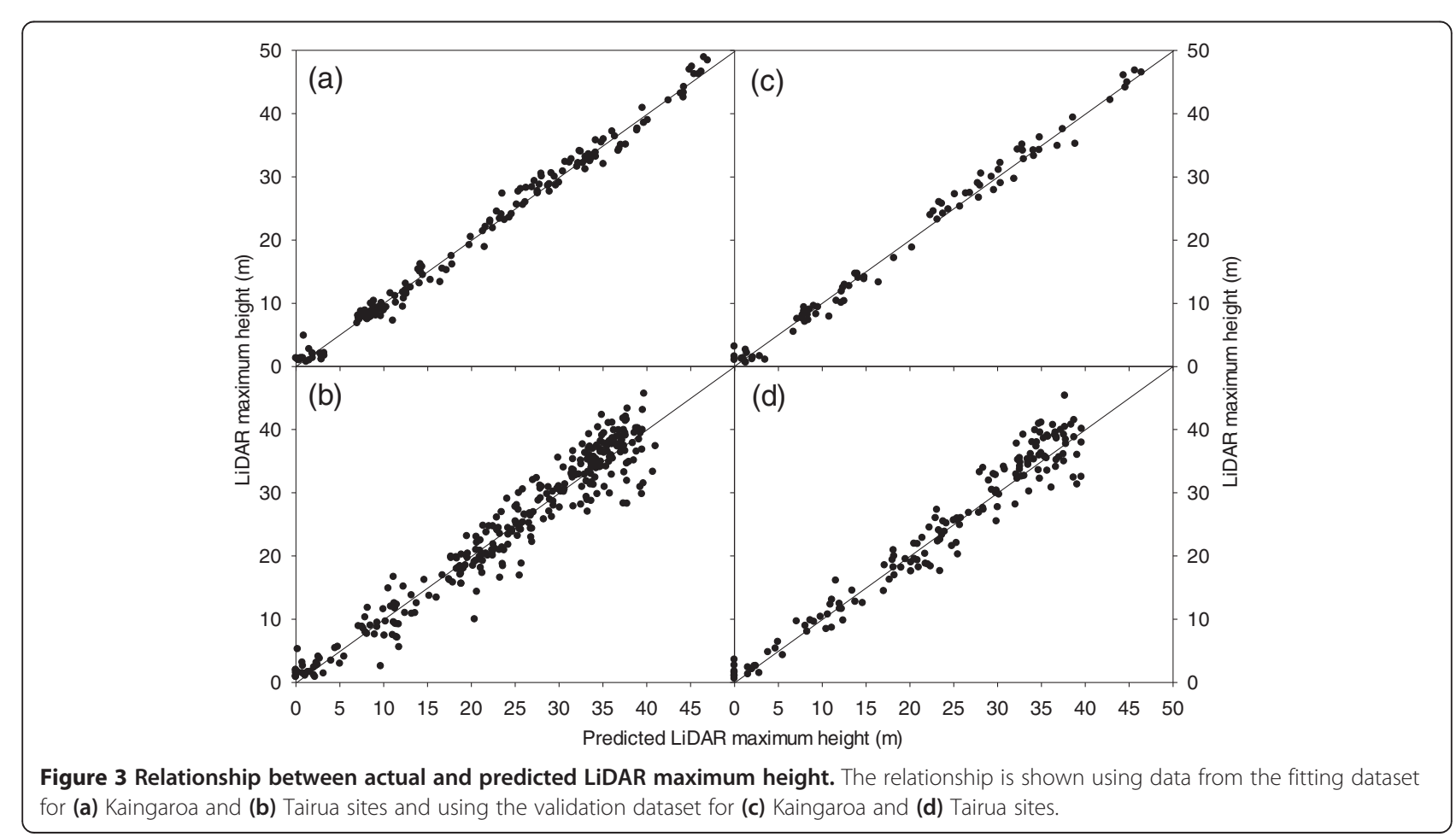




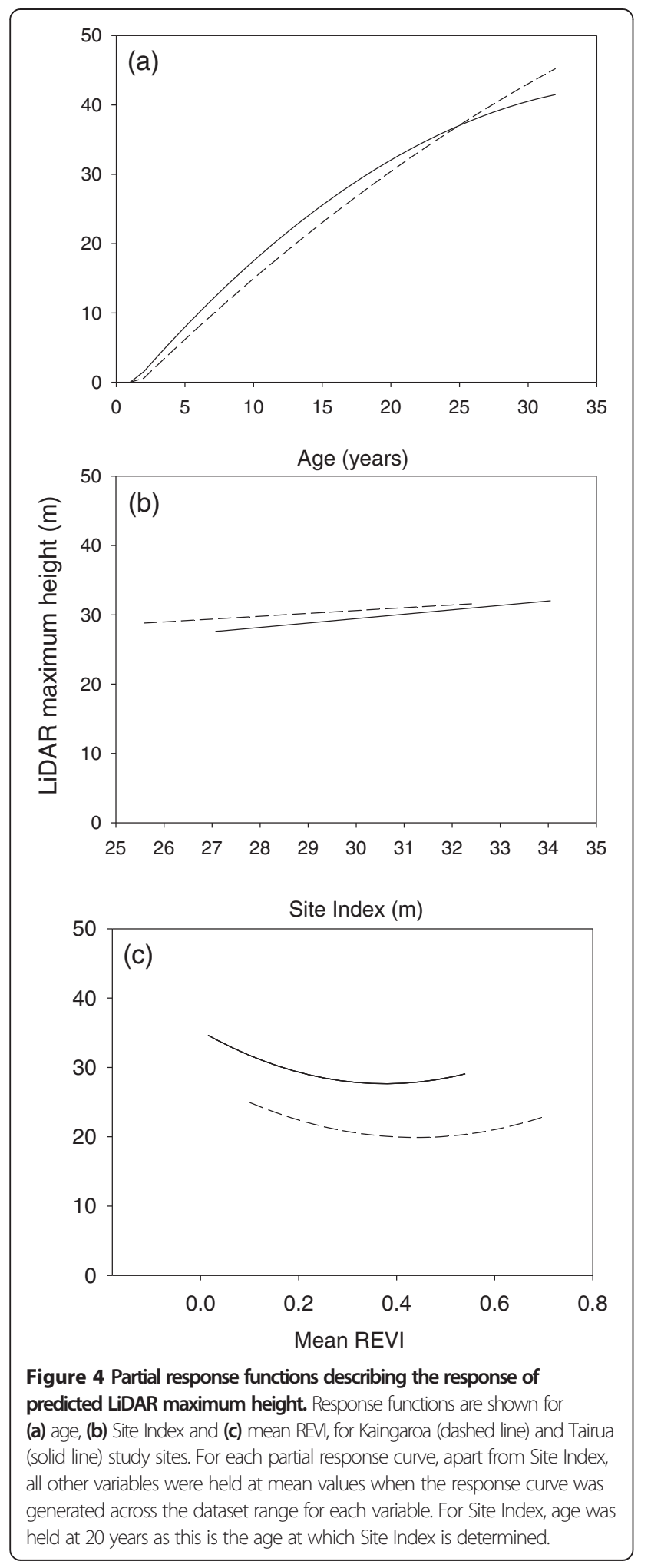

forest level, and even more widely at the national level, with an almost three-fold range (from 15.1 to $42.5 \mathrm{~m}$ ). The relationship between LiDAR height and age will be weaker in forests with greater variability in Site Index.
Inclusion of Site Index in the model allows for more generalised prediction. Empirical height growth models typically use Site Index to scale age-height relationships between sites with differing productivity. Consequently, from a theoretical point of view empirical selection of this variable in the model was sound and reinforced the accuracy of the Site Index layer that was primarily based on productivity relationships with air temperature and rainfall (Palmer, Watt et al. 2009). Age and Site Index should be included within height productivity models given the critical importance of these two variables. In situations where Site Index is not available, use of key environmental variables (such as air temperature and mean annual rainfall) may provide useful surrogates for Site Index.

After accounting for age and Site Index, the strongest correlation was between REVI and $H_{\mathrm{m}}$. The REVI uses a narrow spectral band width along the red edge band that is sensitive to changes in stress and chlorophyll concentrations of different types of vegetation (Chappelle et al. 1992; Gitelson et al. 1996; Carter and Knapp 2001). Previous research using an aerial platform has also identified the red-edge band as providing useful information on photosynthetic vigour (Curran et al. 1990).

Gains in precision were greatest when REVI was combined with both age and Site Index. Within the fitting dataset, relatively substantial gains were obtained over the age-only model at both Kaingaroa (RMSE $=1.29$ vs. $1.73 \mathrm{~m}$ ) and to a lesser extent at the Tairua site (RMSE $=2.96 v s$. $3.13 \mathrm{~m}$ ). The validation process confirmed the importance of REVI at the Kaingaroa site. However gains obtained through adding REVI and Site Index to the base model with age did not result in model improvement at the Tairua site. This is possibly attributable to increased presence of topographic shadow due to the lower sun angle $\left(35^{\circ}\right)$ and undulating terrain over the Tairua site. These factors effectively mitigate the shadow correction process in areas of high relief. This is evident in site differences in REVI where REVI was markedly lower over the Tairua site.

The functional form of the models was similar for both study sites, despite site differences in the magnitude of REVI. This result provides an indication that the same factors influence the relationship at each site. Previous research has shown that REVI is prone to saturation once the canopy has closed (Donoghue and Watt 2006; le Maire et al. 2011). This study demonstrates utility of REVI at ages beyond canopy closure if the variable is combined with age and other spatially derived layers that describe environmental processes and interactions.

Inclusion of satellite-based metrics, such as REVI, in height models allows for fine-scale spatial predictions that can be temporally updated. For example, within stand variation in productivity is not accounted for by age as this is a compartment-level variable. Similarly, while Site Index 
Table 4 Summary of statistics for the four regression models of maximum LiDAR height developed using data from Tairua Forest

\begin{tabular}{|c|c|c|c|c|c|}
\hline \multirow[t]{2}{*}{ Model no } & \multirow[t]{2}{*}{ Variables included } & \multicolumn{2}{|c|}{ Fitting dataset } & \multicolumn{2}{|c|}{ Validation dataset } \\
\hline & & $R^{2}$ & RMSE (m) & $R^{2}$ & RMSE (m) \\
\hline 1 & Age & 0.929 & 3.13 & 0.951 & 2.66 \\
\hline 2 & Age, Site Index & 0.934 & 3.02 & 0.953 & 2.60 \\
\hline 3 & Age, Mean REVI & 0.931 & 3.07 & 0.948 & 2.75 \\
\hline 4 & Age, Site Index, Mean REVI & 0.936 & 2.96 & 0.951 & 2.67 \\
\hline
\end{tabular}

Shown are the coefficient of determination $\left(R^{2}\right)$ and root mean square error (RMSE) for the fitting and validation datasets. All variables in the four models were significant at $\mathrm{P}<0.001$.

partially accounts for productivity variation within stands (at a scale of $100 \mathrm{~m}^{2}$ ) this variable is a static measure that is not sensitive to inter- annual variation in site conditions. In contrast, REVI is available at spatial resolutions that allow for fine-scale predictions of productivity. As the REVI layer can be continuously updated, predictions from repeat acquisitions are sensitive to changes in forest structure caused by growth or changes to the forest canopy caused by wind, snow, fire or disease (Watt and Watt 2011).

The use of a difference index or ratios such as REVI are of particular interest as they provide an effective way (a)

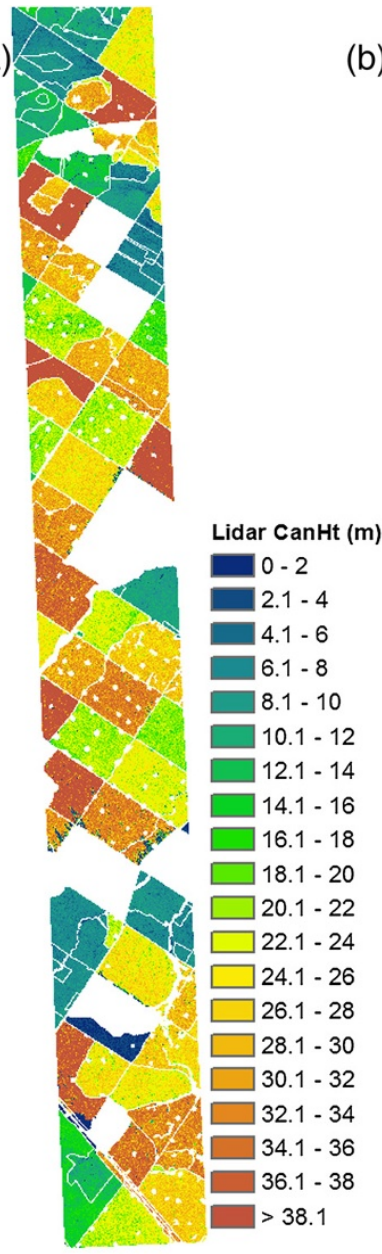

(b)

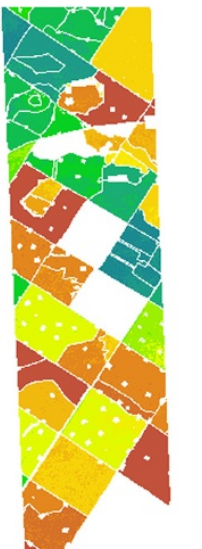

RapidEye CanHt (m)

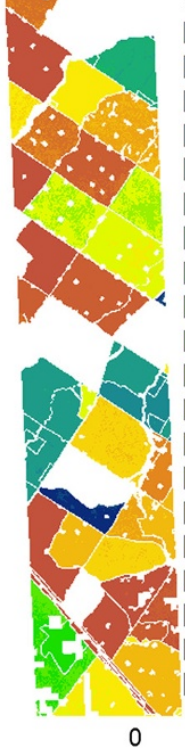

0 - 2

2.1- 4

4.1-6

$6.1-8$

$8.1-10$

$10.1-12$

12.1 - 14

$14.1-16$

$\square 16.1$ - 18

$\square 18.1-20$

$\square 20.1$ - 22

$\square 22.1$ - 24

$\square 24.1$ - 26

$\square 26.1$ - 28

$\square 28.1$ - 30

$\square 30.1$ - 32

$\square 2.1$ - 34

$34.1-36$

$36.1-38$

$>38.1$ (c)

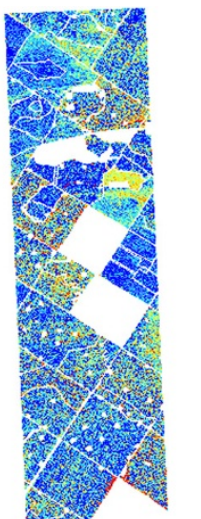

(d)

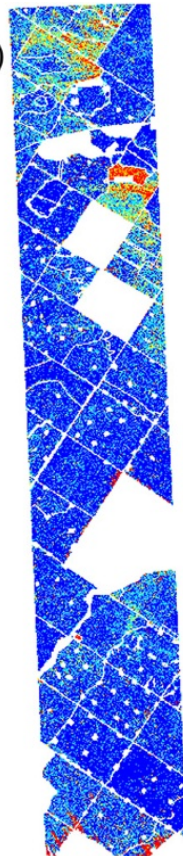

Lidar - RapidEye (m)

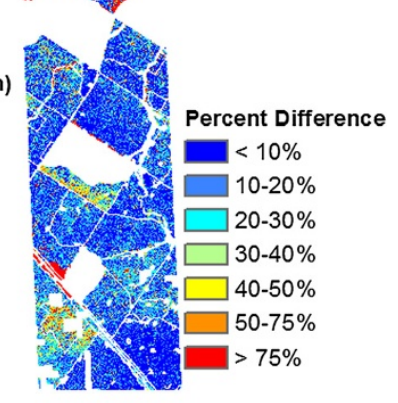

Figure 5 Maps for the Kaingaroa study area. Panels show (a) LiDAR maximum canopy height, (b) predicted canopy height using the full model, (c) absolute differences between LiDAR and predicted height, and (d) absolute differences expressed as a percentage of the LiDAR height. 


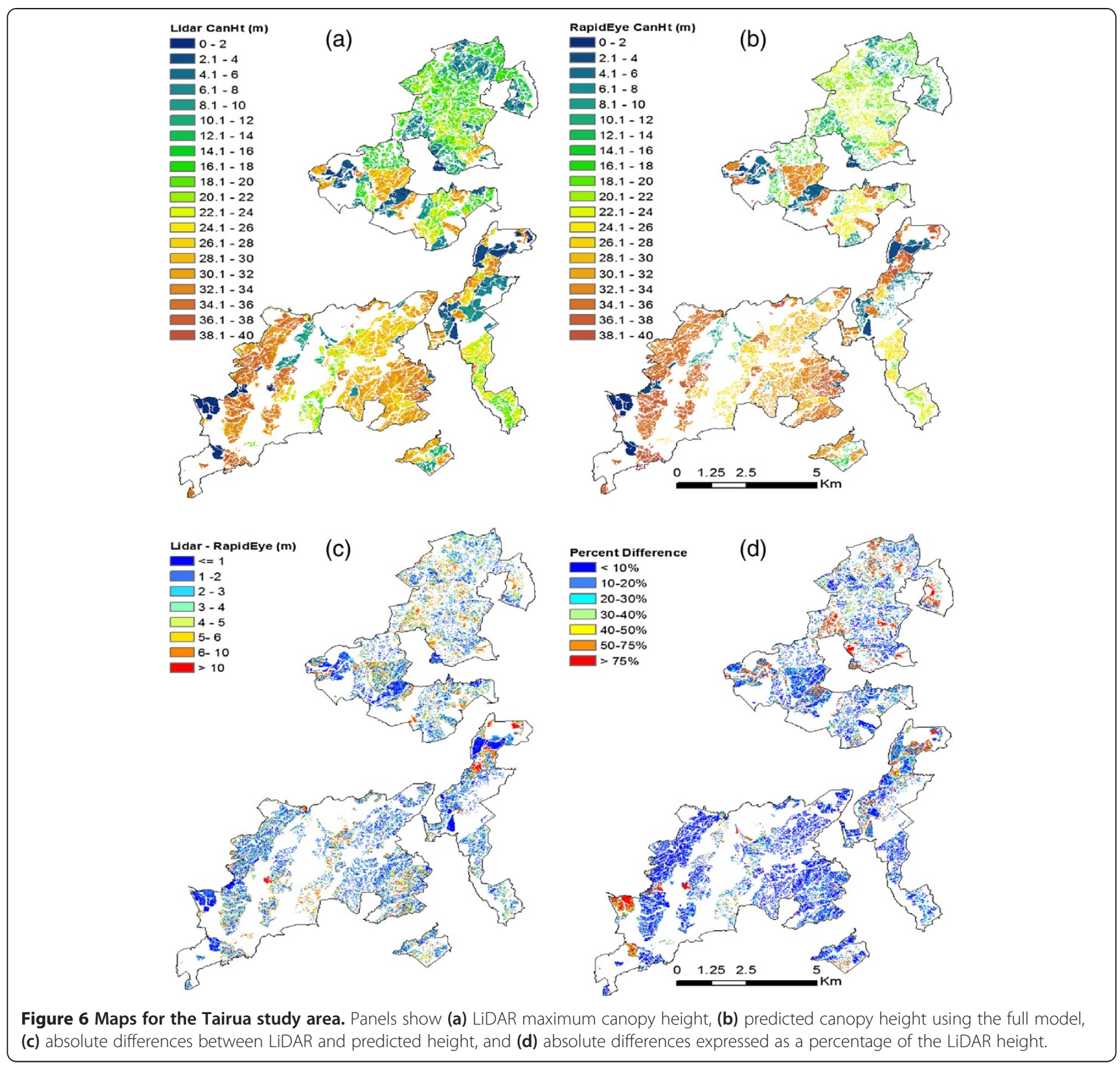

to correct for variations in the reflectance values that may be caused by differences in atmospheric or sun illumination conditions. This partially negates the need to conduct pre-processing steps such as atmospheric corrections. Findings from the current study show that the functional form between REVI and height was very similar between sites although the satellite information used was acquired at different times. These results reinforce the utility of REVI as a general predictor of height growth using data acquired under different atmospheric conditions.

In contrast to the results presented here, previous research has shown that mean height of $P$. radiata can be accurately predicted using only high resolution satellite imagery data (Shamsoddini et al. 2013). Shamsoddini et al. (2013) show strong correlations between mean height and reflectance bands $\left(R^{2}\right.$ of 0.82$)$ and band ratios $\left(R^{2}\right.$ of 0.78$)$ from a WorldView-2 multispectral image. The most precise model of mean height was developed using textural attributes and had a coefficient of determination of 0.93 (Shamsoddini et al. 2013). The approach used by Shamsoddini et al. (2013) is not reliant on up-to-date GIS records, that include recently harvested areas, as the relationships used for prediction are more sensitive to variation between bare ground and forested areas, than those used here that were primarily reliant on stand age derived from the GIS. The approach used in the present 
study is useful in well managed plantations where managers have access to spatial surfaces describing variation in site productivity such as Site Index. Although the approach outlined here is reliant on up to date stand records a methodology has been developed using RapidEye imagery to update recently harvested areas and segregate different species within the stand GIS (Watt and Watt 2011; Watt and Watt 2012). This methodology could be used to update the stand GIS immediately before the models described in this paper are applied to estimate height. The use of a single variable such as REVI from satellite imagery is justified as the simplicity of the relationship may allow generalisation that is not possible with more complex models that include a number of independent variables.

Further research should be undertaken across broader spatial scales that include greater gradients in Site Index to further test the generality of the models developed here. Development of generally applicable regional models of height would be of considerable use to the forestry sector as this approach provides a means of more frequently mapping and monitoring of crop performance. Once this benchmark has been established then subsequent acquisition of imagery should be able to identify clearfell areas not updated in the stand GIS or areas with abiotic or biotic damage. This information would be useful to both resource planners and managers. Frequent coverage from satellite-based systems will also assist in the focussing of LiDAR surveys around more heterogeneous areas (Watt and Watt 2012).

\section{Conclusions}

In conclusion, the retrieval of forest structure information over the lifetime of a planted forest is best achieved by the integration of information from GIS layers with satellite, airborne and ground-based measurements. Through such integration of data into a GIS, foresters have a powerful tool that is capable of providing a rapid overview of a large forest estate. These data provide both a pictorial view of the forest and quantitative analysis that can underpin better informed forest management decisions.

\section{Competing interests}

The authors declare that they have no competing interests.

\section{Authors' contributions}

PW was the primary author. AM and CY extracted the data and produced the maps. MSW undertook the analysis and assisted with the writing. All authors read and approved the final manuscript.

\section{Acknowledgements}

This project was funded within the Intensive Forest Systems project of Future Forests Research Ltd. We thank two anonymous reviewers for providing useful comments that were used to improve the manuscript.

\section{Author details}

${ }^{1}$ Indufor Asia-Pacific Ltd, P.O. Box 105039, Auckland, New Zealand. ${ }^{2}$ Scion, P.O. Box 29237, Fendalton, Christchurch, New Zealand.
Received: 5 April 2013 Accepted: 27 August 2013

Published: 04 Sep 2013

\section{References}

Baccini, A, Laporte, N, Goetz, SJ, Sun, M, \& Dong, H. (2008). A first map of tropical Africa's above-ground biomass derived from satellite imagery. Environmental Research Letters, 3(4). doi:10.1088/1748-9326/3/4/045011.

Carter, GA, \& Knapp, AK. (2001). Leaf optical properties in higher plants: linking spectral characteristics to stress and chlorophyll concentration. American Journal of Botany, 88(4), 677-684. doi:10.2307/2657068.

Chappelle, EW, Kim, MS, \& Mcmurtrey, JE. (1992). Ration analysis of reflectance spectra (RARS): an algorithm for the remote estimation of the concentrations of chlorophyll a, chlorophyll B, and carotenoids in soybean leaves. Remote Sensing and Environment, 39, 239-247.

Chen, Q, Baldocchi, D, Gong, P, \& Kelly, M. (2006). Isolating individual trees in a savanna woodland using small footprint lidar data. Photogrammetric Engineering and Remote Sensing, 72, 923-932.

Coops, NC, Wulder, MA, Culvenor, DS, \& St-Onge, B. (2004). Comparison of forest attributes extracted from fine spatial resolution multispectral and lidar data. Canadian Journal Of Remote Sensing, 30, 855-866.

Curran, PJ, Dungan, JL, \& Gholz, HL. (1990). Exploring the relationship between reflectance Red edge and chlorophyll content in slash pine. Tree Physiology, $7(1-4), 33-48$.

Donoghue, DNM, \& Watt, PJ. (2006). Using LiDAR to compare forest height estimates from IKONOS and landsat ETM+ data in Sitka spruce plantation forests. International Journal Of Remote Sensing, 27(11), 2161-2175.

Dzierzon, H, \& Mason, E G. (2006). Towards a nationwide growth and yield model for radiata pine plantations in New Zealand. Canadian Journal of Forest Research, 36, 2533-2543.

Eid, T, Gobakken, T, \& Naesset, E. (2004). Comparing stand inventories for large areas based on photo-interpretation and laser scanning by means of costplus-loss analyses. Scandinavian Journal of Forest Research, 19(6), 512-523.

Gebreslasie, MT, Ahmed, FB, \& van Aardt, JAN. (2010). Predicting forest structural attributes using ancillary data and ASTER satellite data. International Journal Of Applied Earth Observation And Geoinformation, 12, S23-S26. doi:10.1016/j. jag.2009.11.006.

Gitelson, AA, Kaufman, YJ, \& Merzlyak, MN. (1996). Use of a green channel in remote sensing of global vegetation from EOS-MODIS. Remote Sensing Of Environment, 58(3), 289-298. doi:10.1016/S0034-4257(96)00072-7.

Hall, SA, Burke, IC, Box, DO, Kaufmann, MR, \& Stoker, JM. (2005). Estimating stand structure using discrete-return lidar: an example from low density, fire prone ponderosa pine forests. Forest Ecology and Management, 208(1-3), 189-209.

Holmgren, J, Nilsson, M, \& Olsson, H. (2003). Estimation of tree height and stem volume on plots using airborne laser scanning. Forest Science, 49, 419-428.

Holmgren, J, \& Persson, A. (2004). Identifying species of individual trees using airborne laser scanner. Remote Sensing Of Environment, 90(4), 415-423.

Hudak, AT, Lefsky, MA, Cohen, WB, \& Berterretche, M. (2002). Integration of lidar and landsat ETM plus data for estimating and mapping forest canopy height. Remote Sensing Of Environment, 82(2-3), 397-416.

Hyyppä, J, Kelle, O, Lehikoinen, M, \& Inkinen, M. (2001). A segmentation-based method to retrieve stem volume estimates from 3-D tree height models produced by laser scanners. leee Transactions on Geoscience and Remote Sensing, 39, 969-975.

Kayitakire, F, Hamel, C, \& Defourny, P. (2006). Retrieving forest structure variables based on image texture analysis and IKONOS-2 imagery. Remote Sensing of Environment, 102(3-4), 390-401. doi:10.1016/j.rse.2006.02.022.

le Maire, G, Marsden, C, Nouvellon, Y, Grinand, C, Hakamada, R, Stape, JL, et al. (2011). MODIS NDVI time-series allow the monitoring of eucalyptus plantation biomass. Remote Sensing Of Environment, 115(10), 2613-2625. doi:10.1016/j.rse.2011.05.017

Leathwick, J, Morgan, F, Wilson, G, Rutledge, D, McLeod, M, \& Johnston, K. (2002). Land environments of New Zealand: a technical guide (p. 184). Hamilton: Ministry for the Environment, Wellington, and Manaaki Whenua Landcare Research.

Leathwick, J, Wilson, G, Rutledge, D, Wardle, P, Morgan, F, Johnston, K., et al. (2003). Land environments of New Zealand. Hamilton: Ministry for the Environment, Wellington, and Manaaki Whenua Landcare Research.

Leathwick, JR, \& Stephens, RTT. (1998). Climate surfaces for New Zealand (Landcare Res. Contract report LC9798/126, p. 19). Lincoln, New Zealand: Landcare Research. 
Lim, KS, \& Treitz, PM. (2004). Estimation of aboveground forest biomass from airborne discrete return laser scanner data using canopy-based quantile estimators. Scandinavian Journal of Forest Research, 19, 558-570.

McGaughey, RJ, \& Carson, WW. (2003). Fusing LIDAR data, photographs, and other data using 2D and $3 D$ visualization techniques (Proceedings of terrain data: applications and visualization - making the connection; October 28-30, 2003, pp. 16-24). Charleston, South Carolina: Bethesda, MD: American Society for Photogrammetry and Remote Sensing.

McRoberts, RE, \& Tomppo, E. (2007). Remote sensing support for national forest inventories. Remote Sensing Of Environment, 110, 412-419.

Mitchell, ND. (1991). The derivation of climate surfaces for New Zealand, and their application to the bioclimatic analysis of the distribution of kaur (Agathis australis). Journal of the Royal Society of New Zealand, 21, 13-24.

Naesset, E. (2002). Predicting forest stand characteristics with airborne scanning laser using a practical two-stage procedure and field data. Remote Sensing of Environment, 80(1), 88-99.

Naesset, E, \& Bjerknes, KO. (2001). Estimating tree heights and number of stems in young forest stands using airborne laser scanner data. Remote Sensing Of Environment, 78(3), 328-340.

Nilsson, M. (1996). Estimation of tree heights and stand volume using an airborne LiDAR system. Remote Sensing Of Environment, 56(1), 1-7.

Ozdemir, I. (2008). Estimating stem volume by tree crown area and tree shadow area extracted from pan-sharpened quickbird imagery in open Crimean juniper forests. International Journal Of Remote Sensing, 29(19), 5643-5655. doi:10.1080/01431160802082155.

Palmer, D, Hock, B, Kimberley, M, Watt, M, Lowe, D, \& Payn, T. (2009). Comparison of spatial prediction techniques for developing Pinus radiata productivity surfaces across New Zealand. Forest Ecology and Management, 258(9), 20462055. doi:10.1016/j.foreco.2009.07.057.

Palmer, DJ. (2008). Development of national extent terrain attributes (TANZ), soil water balance surfaces (SWatBal), and environmental surfaces, and their application for spatial modelling of Pinus radiata productivity across New Zealand (p. 410). Hamilton, New Zealand: PhD thesis, University of Waikato.

Palmer, DJ, Watt, MS, Hock, BK, \& Lowe, DJ. (2009). A dynamic framework for spatial modelling Pinus radiata soil water balance (SWatBal) across New Zealand. Scion Bulletin, 234, 93.

Palmer, DJ, Watt, MS, Kimberley, MO, \& Dungey, HS. (2012). Predicting the spatial distribution of Sequoia sempervirens productivity in New Zealand. New Zealand Journal of Forestry Science, 42, 81-89.

Persson, A, Holmgren, J, \& Soderman, U. (2002). Detecting and measuring individual trees using an airborne laser scanner. Photogrammetric Engineering And Remote Sensing, 68(9), 925-932.

Popescu, SC, Wynne, RH, \& Scrivani, JA. (2004). Fusion of small-footprint lidar and multispectral data to estimate plot-level volume and biomass in deciduous and pine forests in Virginia, USA. Forest Science, 50, 551-565.

Popescu, SC, \& Zhao, K. (2008). A voxel-based lidar method for estimating crown base height for deciduous and pine trees. Remote Sensing Of Environment, 112, 767-781

Riano, D, Chuvieco, E, Salas, J, \& Aguado, I. (2003). Assessment of different topographic corrections in Landsat TM data for mapping vegetation types. IEEE Trans. Geosci. Remote Sens, 41, 1056-1061.

Roberts, SD, Dean, TJ, Evans, DL, McCombs, JW, Harrington, RL, \& Glass, PA. (2005). Estimating individual tree leaf area in loblolly pine plantations using LiDAR-derived measurements of height and crown dimensions. Forest Ecology and Management, 213(1-3), 54-70.

SAS-Institute-Inc. (2000). SAS/STAT User's guide: version 8 (Volumes 1, 2 and 3, p. 3884). Cary, North Carolina: SAS Institute Inc.

Shamsoddini, A, Trinder, JC, \& Turner, R. (2013). Pine plantation structure mapping using WorldView-2 multispectral image. International Journal of Remote Sensing, 34(11), 3986-4007. doi:10.1080/01431161.2013.772308.

Tait, A, Henderson, R, Turner, R, \& Zheng, Z. (2006). Thin plate smoothing interpolation of daily rainfall for New Zealand using a climatological rainfall surface. International Journal of Climatology, 26, 2097-2115.

Watt, MS, \& Palmer, DJ. (2012). Use of regression kriging to develop a carbon: nitrogen ratio surface for New Zealand. Geoderma, 183, 49-57. doi:10.1016/j.geoderma.2012.03.013.

Watt, MS, Palmer, DJ, Dungey, H, \& Kimberley, MO. (2009). Predicting the spatial distribution of Cupressus lusitanica productivity in New Zealand. Forest Ecology and Management, 258(3), 217-223. doi:10.1016/j.foreco.2009.04.003.
Watt, PJ. (2005). An evaluation of LiDAR and optical satellite data for the measurement of structural attributes in British upland conifer plantation forestry (Doctoral thesis). England: Department of Geography, University of Durham.

Watt, PJ, \& Watt, MS. (2011). Applying satellite imagery for forest planning. New Zealand Journal of Forestry, 56, 23-25.

Watt, PJ, \& Watt, MS. (2012). Forest planning applications using high resolution satellite data. New Zealand Journal of Forestry, 57, 32-40.

Yu, XW, Hyyppa, J, Kaartinen, H, \& Maltamo, M. (2004). Automatic detection of harvested trees and determination of forest growth using airborne laser scanning. Remote Sensing Of Environment, 90(4), 451-462.

Zhao, K, \& Popescu, S. (2009). Lidar-based mapping of leaf area index and its use for validating GLOBCARBON satellite LAI product in a temperate forest of the southern USA. Remote Sensing Of Environment, 113, 1628-1645.

Zheng, DL, Rademacher, J, Chen, JQ, Crow, T, Bresee, M, le Moine, J, et al. (2004). Estimating aboveground biomass using landsat 7 ETM+ data across a managed landscape in northern Wisconsin, USA. Remote Sensing Of Environment, 93(3), 402-411. doi:10.1016/j.rse.2004.08.008.

10.1186/1179-5395-43-11

Cite this article as: Watt et al.: Development of regional models of Pinus radiata height from GIS spatial data supported with supplementary satellite imagery. New Zealand Journal of Forestry Science 2013, 43:11

\section{Submit your manuscript to a SpringerOpen ${ }^{\circ}$ journal and benefit from:}

- Convenient online submission

Rigorous peer review

- Immediate publication on acceptance

- Open access: articles freely available online

- High visibility within the field

- Retaining the copyright to your article

Submit your next manuscript at $>$ springeropen.com 